\title{
Two new antifungal metabolites produced by Sparassis crispa in culture and in decayed trees
}

\author{
S. Woodward, ${ }^{*}$ H. Y. Sultan,$\dagger$ D. K. Barrett and R. B. Pearce $\ddagger$ \\ Oxford Forestry Institute, Department of Plant Sciences, University of Oxford, South Parks Road, \\ Oxford $O X 13 R B, U K$
}

(Received 15 May 1992; revised 10 September 1992; accepted 22 September 1992)

\begin{abstract}
The basidiomycete fungus Sparassis crispa produced three antifungal compounds during submerged culture in $2 \%$ malt broth. One compound appeared to be sparassol (methyl-2-hydroxy-4-methoxy-6-methylbenzoate), first characterized in 1924. The other two, termed ScI and ScII, exhibited considerably greater antifungal activity than did sparassol against Cladosporium cucumerinum, and were characterized as methyl-2,4-dihydroxy-6methylbenzoate (methyl orsellinate) and an incompletely determined methyl-dihydroxy-methoxy-methylbenzoate, respectively. Both compounds were found in the decayed wood of trees, where their presence was diagnostic of $S$. crispa infection. The possible ecological role of these compounds is discussed.
\end{abstract}

\section{Introduction}

Although largely neglected, the first reported isolation and characterization of a microbially produced antibiotic, antedating comparable work on penicillin (Hütterman, 1987), was from the wood-rotting basidiomycete Sparassis crispa (formerly $S$. ramosa). Falck (1923) observed that, unlike cultures of other species, $S$. crispa did not become contaminated with other fungi, and isolated a compound that occurred as crystals in and on the medium of old cultures. This compound exhibited mycocidal activity, although full data on its biological action remained unpublished (cf. Cwielong, 1986; Hütterman, 1987). The compound, given the trivial name sparassol, was shown to be methyl-2-hydroxy4-methoxy-6-methylbenzoate (Wedekind \& Fleischer, 1923, 1924). In subsequent screenings for antibiotic production, $S$. crispa has been noted as moderately active (Wilkins \& Harris, 1944; Robbins et al., 1945; Hervey, 1947), and suppression of growth of Bacillus subtilis on agar media pre-inoculated with $S$. crispa has been attributed to sparassol (Siepmann, 1987).

* Author for correspondence. Present address: Department of Forestry, University of Aberdeen, St Machar Drive, Aberdeen AB9 2UD, UK. Tel. (0224) 272669; fax (0224) 272685.

$\dagger$ Present address: MRC Environmental Epidemiology Unit, University of Southampton, Southampton General Hospital, Southampton SO9 4XY, UK.

$\ddagger$ Present address: School of Biological Sciences, The University of Birmingham, Edgbaston, Birmingham B15 2TT, UK.
S. crispa causes a brown root- and butt-rot in living conifers, closely similar to damage caused by Phaeolus schweinitzii. Both fungi can cause significant losses in managed conifer forest, but without basidiocarps or cultures, it is difficult to determine which species is responsible for the damage (Phillips \& Burdekin, 1982). Although $S$. crispa has been less intensively studied than $P$. schweinitzii, it appears to resemble the latter in having little or no ability to invade the living tissues of its host (Rayner \& Boddy, 1988), and is generally restricted to the older, dead wood of standing trees.

Antibacterial and antifungal compounds have been detected in fruit bodies and cultures of many woodinhabiting fungi (Wilkins \& Harris, 1944; Wilkins, 1945, 1946; Robbins et al., 1945; Mathieson, 1946; Hervey, 1947; Brian, 1951; Broadbent, 1968). However, the significance of these compounds in natural environments is uncertain. Uncharacterized antifungal activity from the aquatic (non-basidiomycete) fungus Massarina aquatica has been reported in colonized oak wood blocks, and in culture filtrates (Fisher \& Anson, 1983). The colonized blocks inhibited the growth of several other fungi which are found in the same habitat, suggesting that production of the antifungal substances may confer an ecological advantage on $M$. aquatica under natural conditions. The root- and butt-rot pathogen Heterobasidion annosum produces inhibitory compounds in the presence of plant cells or antagonistic fungi (Sonnenbichler et al., 1989), but the inference that these are 'ecological metabolites' was based only on cultural studies. 
This paper describes the characterization of two further antifungal metabolites from $S$. crispa, and their production both in culture and in naturally decayed wood.

\section{Methods}

Organisms. Sparassis crispa isolates 5B and 5C were from laboratory stocks, obtained from decayed conifer trees some years previous to this study, and maintained by repeated subculture on $2 \%$ malt agar $(2 \%$, $\mathrm{w} / \mathrm{v}$, Oxoid malt; $1.5 \%, \mathrm{w} / \mathrm{v}$, Oxoid agar no. 3 ), with storage at $4{ }^{\circ} \mathrm{C}$. Additional isolates, $5 \mathrm{E}-5 \mathrm{I}$, were isolated from decayed wood of European larch (Larix decidua) trees from Bagley Wood, Oxfordshire, UK, by plating small pieces (about $5 \mathrm{~mm}^{2}$ ) of wood removed aseptically from near the margin of brown rot lesions on $3 \%$ malt agar. Decay fungi isolated in this way were identified on the basis of their characteristics in culture (Stalpers, 1978).

The wood-decaying basidiomycetes Armillaria gallica, A. mellea, A. ostoyae, A. tabescens, Coriolus versicolor, Heterobasidion annosum, Hypholoma fasciculare, Inonotus dryadeus, Phaeolus schweinitzii, Rigidoporus ulmarius and Stereum sanguinolentum, and the ascomycete root pathogen Rhizina undulata, were from laboratory stocks, maintained and grown as above. Botrytis cinerea and Cladosporium cucumerinum, also laboratory stock isolates, were maintained and sporulated on Botrytis medium X (Last \& Hanley, 1956).

Antibiotic production in culture. S. crispa, strains $5 \mathrm{~B}$ and $5 \mathrm{C}$, were grown as stationary submerged cultures in $2 \%$ malt extract (Oxoid) broth $(50 \mathrm{ml})$ in $250 \mathrm{ml}$ Erlenmeyer flasks, at $25^{\circ} \mathrm{C}$ in darkness.

Samples $(0.8 \mathrm{ml})$ were withdrawn from culture flasks, mixed with methanol $(1.2 \mathrm{ml})$ and stored at $-20^{\circ} \mathrm{C}$ prior to HPLC analysis. Three replicate flasks were used at each sampling time, and the mycelial dry weight of these cultures was determined. Fungal mycelium was collected by filtration through muslin, rinsed with water and dried to constant weight at $80^{\circ} \mathrm{C}$.

Isolation of antibiotic compounds produced by S. crispa. Culture filtrates from 28-d-old cultures of $S$. crispa 5B, grown as above, were partitioned twice against $50 \mathrm{ml}$ vols of redistilled chloroform. Combined chloroform phases were evaporated to dryness under reduced pressure at $30^{\circ} \mathrm{C}$, and the residue redissolved in a small volume of ethyl acetate.

Antifungal compounds were detected in these extracts by direct bioassay with Cladosporium cucumerinum on developed TLC plates (Homans \& Fuchs, 1970). Aluminium-backed TLC plates (silica gel $60 \mathrm{~F}_{254}, 0.2 \mathrm{~mm}$ thick) were loaded with the ethyl acetate extract $(0.5-2.5 \mathrm{ml}$ culture volume equivalent) and developed. Two alternative solvent systems were used: A, chloroform/methanol $(96: 4, v / v)$; B, cyclohexane/ethyl acetate $(1: 1, v / v)$. Air-dried plates were sprayed with dense conidial suspensions of $C$. cucumerinum in half-strength Czapek Dox salts containing $15 \mathrm{~g}$ sucrose $\mathrm{l}^{-1}$.

The two most active antifungal compounds detected on bioassays were purified by sequential preparative TLC on silica gel $60 \mathrm{~F}_{254}$ plates $(0.5 \mathrm{~mm}$ thick), using the two solvent systems. Compounds were eluted from the silica gel with methanol and crystallized by evaporation under reduced pressure.

Characterization of antibiotic compounds. UV absorption spectra were obtained for the purified antifungal compounds. These compounds were further characterized by mass spectrometry and ${ }^{1} \mathrm{H}$ nuclear magnetic resonance.

Antifungal activity of pure compounds. Spore germination tests against Botrytis cinerea were done as described by Rossall \& Mansfield (1978), using the active compounds at a concentration of $100 \mu \mathrm{g} \mathrm{ml}^{-1}$ in the assay solution. Assays against mycelial growth of Heterobasidion annosum were done in flat-bottomed glass tubes $(25 \mathrm{~mm}$ diam.) containing $2.5 \mathrm{ml} \mathrm{2 \%}$ malt extract (Oxoid) broth (Woodward \& Pearce, 1988), with $100 \mu \mathrm{g}$ of active compound incorporated.

Interactions of $S$. crispa with other fungi. Interactions between $S$ crispa and other wood-inhabiting fungi were examined in dual culture on Malt Extract Agar (Difco). Petri dishes ( $90 \mathrm{~mm}$ diam.) containing approximately $25 \mathrm{ml}$ of medium were inoculated eccentrically with $S$. crispa and, except with Armillaria spp., incubated for $14 \mathrm{~d}\left(22^{\circ} \mathrm{C}\right.$, in darkness) before inoculation with other fungi $60 \mathrm{~mm}$ from the Sparassis inoculation site. Effects on the growth of these fungi were assessed after further incubation for $14 \mathrm{~d}$. In tests with $A$. gallica, $A$. mellea. $A$. ostoyae and $A$. tabescens, the fungi were inoculated simultaneously and examined after $28 \mathrm{~d}$.

Estimation of antibiotics from decayed wood. Wood from a windsnapped Sitka spruce (Picea sitchensis) tree from Bagley Wood, exhibiting an advanced brown cubical rot attributable to $S$. crispa (identified by cultural characteristics after isolation, and from basidiomes produced on the stump), was extracted in methanol ( 5 vols). Extracts were concentrated by evaporation under reduced pressure, and antifungal activity was detected on TLC plates by bioautography with $C$. cucumerinum. Samples equivalent to $1 \mathrm{~g}$ fresh wt decayed wood were loaded, and developed in solvent system B.

The compounds in wood extracts were quantified spectrophotometrically $\left(A_{266}\right)$ after methanol elution from preparative TLC plates.

Quantification of antibiotics in culture filtrates using HPLC. Total antibiotics in culture filtrate samples were determined by reverse phase HPLC. Aliquots $(20 \mu \mathrm{l})$ were separated isocratically on a NovaPakCl 8 Radial-Pak cartridge column, $100 \mathrm{~mm} \times 8 \mathrm{~mm}$ i.d.. protected by a $\mu$-Bondapak C18 Guard-Pak cartridge pre-column (Waters). The solvent mixture, $60 \%(\mathrm{v} / \mathrm{v})$ methanol in water, was pumped at a flow rate of $1.5 \mathrm{ml} \mathrm{min}$, and eluting compounds were detected by absorbance at $266 \mathrm{~nm}$. Samples were injected at intervals of $10 \mathrm{~min}$ : the column was washed $(100 \%$ methanol, $10 \mathrm{~min})$ after every 10 determinations. The two antibiotic compounds, which eluted as a single, shouldered, peak, were quantified on a peak area basis against an external standard of the compounds mixed in their naturally occurring proportions.

Detection of antibiotics in decayed wood using HPLC. Samples of brown-rotted wood from felled coniferous trees [mainly, but not exclusively, European larch (Larix decidua)] from Bagley Wood were extracted in 2 vols (w/v) methanol for $24 \mathrm{~h}$ at $4{ }^{\circ} \mathrm{C}$. Samples $(20 \mu \mathrm{l})$ of the resulting extract were separated using reverse-phase HPLC as previously, but with gradient elution. The initial solvent was $30 \%(\mathrm{v} / \mathrm{v})$ aqueous methanol, increasing linearly to $100 \%$ methanol over $20 \mathrm{~min}$. This solvent composition was maintained for $5 \mathrm{~min}$ before returning to the starting conditions (via 100\% water) over a total cycle (including re-equilibration) of $40 \mathrm{~min}$. Purified samples of the antibiotic compounds were used as external standards.

Isolation of sparassol. For use as a chromatography standard for comparison with the antibiotics isolated in this study, a sample of sparassol was obtained from 6-9-month-old cultures of $S$. crispa $5 \mathrm{G}$ on $2 \%$ malt agar slopes, grown initially at $22{ }^{\circ} \mathrm{C}$ for about 1 month, then maintained at $4-8^{\circ} \mathrm{C}$. Crystals, produced abundantly on the surface of these cultures, were harvested mechanically and dissolved in methanol.

\section{Results}

\section{Antifungal antibiotics produced by Sparassis crispa in culture}

A large zone of inhibition was observed at $R_{F} 0 \cdot 50$, and a minor inhibition zone at $R_{F} 0.67$ on TLC plates loaded 
with organic phase extracts from submerged cultures of S. crispa strain 5B, developed in solvent system A and bioassayed with Cladosporium cucumerinum. Solvent system B resolved the large inhibition zone into two major active compounds, with $R_{F}$ values of 0.44 and 0.53 . The minor zone had an $R_{F}$ of 0.66 in this system. All antifungal zones corresponded to areas of extinction under UV light. Sparassol did not give a strong inhibition zone on bioassay plates at the (undetermined) concentration used. The $R_{F}$ of sparassol was 0.64 and 0.70 in solvent systems $\mathrm{A}$ and $\mathrm{B}$, respectively. The two major antifungal compounds, neither of which could be equated with sparassol, were termed $\mathrm{ScI}\left(R_{F}\right.$ in $\left.\mathrm{B}=0 \cdot 44\right)$ and $\mathrm{ScII}$ $\left(R_{F}\right.$ in $\left.\mathrm{B}=0.53\right)$.

When purified from TLC plates, these compounds were obtained as pale yellow crystals. Yields (per litre of culture medium) of $26.5 \mathrm{mg}$ (ScI) and $35.5 \mathrm{mg}$ (ScII) were obtained.

ScI and ScII had HPLC retention times of 13.8 and $14.2 \mathrm{~min}$, respectively, when eluted under gradient conditions. Sparassol had a retention time of $18.2 \mathrm{~min}$. All these compounds were present in 6-week-old culture filtrates of S. crispa.

\section{Chemical and physical properties of antifungal compounds}

ScI. Methyl-2,4-dihydroxy-6-methylbenzoate (methyl orsellinate). Fig. $1(b) . \mathrm{C}_{9} \mathrm{H}_{10} \mathrm{O}_{4}$; m.p. $137-139^{\circ} \mathrm{C}$; UV $\lambda$ $\mathrm{MeOH}_{\max } \mathrm{nm}(\log \varepsilon) 301$ (3.51), 264 (3.94), 229 (3.43); precise mass measurement $M^{+} 182.0551$; MS (electron impact $40 \mathrm{eV}) \mathrm{m} / \mathrm{z} 182\left(\mathrm{M}^{+}, 46 \%\right), 181$ (14), 152 (28), 151 (36), 150 (100), 131 (23), 122 (34); 'H NMR $\left(200 \mathrm{MHz}, \mathrm{CDCl}_{3}\right.$, TMS internal standard) $\delta 2.49$ $(3 \mathrm{H}, \mathrm{s}, \mathrm{Me}), 3.92(3 \mathrm{H}, \mathrm{s}, \mathrm{MeO}-), 6.23(1 \mathrm{H}, \delta, \mathrm{Ar}-\mathrm{H}$, $J=2.9 \mathrm{~Hz}), 6.28(1 \mathrm{H}, \delta, \quad \mathrm{Ar}-\mathrm{H}, J=2.9 \mathrm{~Hz}), 11.73$ $(1 \mathrm{H}, \mathrm{s}$, chelated $\mathrm{Ar}-\mathrm{OH})$.

ScII. Methyl-dihydroxy-methoxy-methylbenzoate (substitution pattern not determined except for hydroxy- in the 2-position), Fig. $1(c) . \mathrm{C}_{10} \mathrm{H}_{12} \mathrm{O}_{5} ; \mathrm{UV} \lambda$ $\mathrm{MeOH}_{\max } \mathrm{nm}(\log \varepsilon) 302$ (3.36), 268 (3.96), 224 (3.95); precise mass measurement $M^{+} 212.0671$; MS (electron impact $40 \mathrm{eV}) \mathrm{m} / \mathrm{z} 212\left(M^{+} 49 \%\right), 181(35), 180(95), 165$ (25), 152 (100), 151 (82), 150 (62), 137 (48), $122(26) ;{ }^{1} \mathrm{H}$ NMR (200 MHz, $\mathrm{CDCl}_{3}$, TMS internal standard) $: \delta 2 \cdot 46$ $(3 \mathrm{H}, \mathrm{s}, \mathrm{Me}), 3.94\left(6 \mathrm{H}, \mathrm{s}, 2^{*} \mathrm{MeO}-\right.$ degenerate $), 6.36$ $(1 \mathrm{H}, \mathrm{s}, \mathrm{Ar}-\mathrm{H}), 11.93(1 \mathrm{H}, \mathrm{s}$, chelated $\mathrm{OH})$.

Sparassol (for comparison). Methyl-2-hydroxy-4methoxy-6-methylbenzoate. Fig. $\quad 1(a) . \quad \mathrm{C}_{10} \mathrm{H}_{12} \mathrm{O}_{4}$. (Wedekind \& Fleischer, 1924.)

\section{Antifungal activity of ScI and ScII}

The effects of these compounds on germ-tube growth in (a) Sparassol

(Methyl-2-hydroxy-

4-methoxy-6-methylbenzoate)

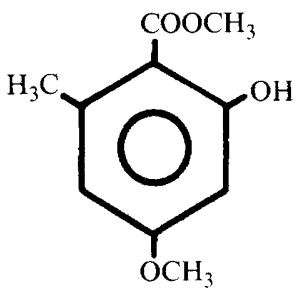

(b) $\mathrm{ScI}$

(Methyl-2, 4-dihydroxy6-methylbenzoate)

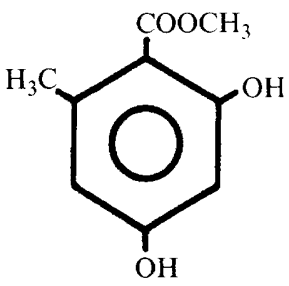

(c) $\mathrm{ScII}$ (Methyl-dihydroxymethoxy-methylbenzoate)

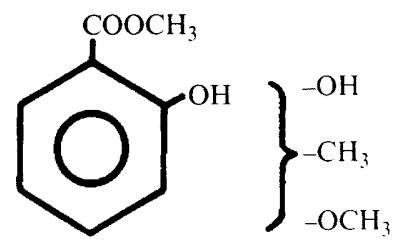

Fig. 1. Chemical structures of (a) sparassol, (b) ScI and (c) ScII.

Botrytis cinerea are shown in Table 1. At the concentration used $\left(100 \mu \mathrm{g} \mathrm{ml}^{-1}\right)$, ScI showed greater activity than ScII against $B$. cinerea. At this concentration, the inhibitory effects of these compounds against mycelial growth of Heterobasidion annosum were less, but remained significant (Table 1).

\section{Interactions of $S$. crispa with other fungi}

A range of responses to pairing with $S$. crispa was observed (Fig. 2). Growth of $H$. annosum was almost completely suppressed, and that of Ionotus dryadeus and Rigidoporus ulmarius markedly inhibited. Mutual growth inhibition was evident with Armillaria gallica, A. mellea, $A$. ostoyae and Stereum sanguinolentum. With $A$. tabescens, Coriolus versicolor, Hypholoma fasciculare. Phaeolus schweinitzil and Rhizina undulata, no gross inhibition was observed prior to contact, although $P$. schweinitzii exhibited a strong incompatibility response along the interaction interface. 

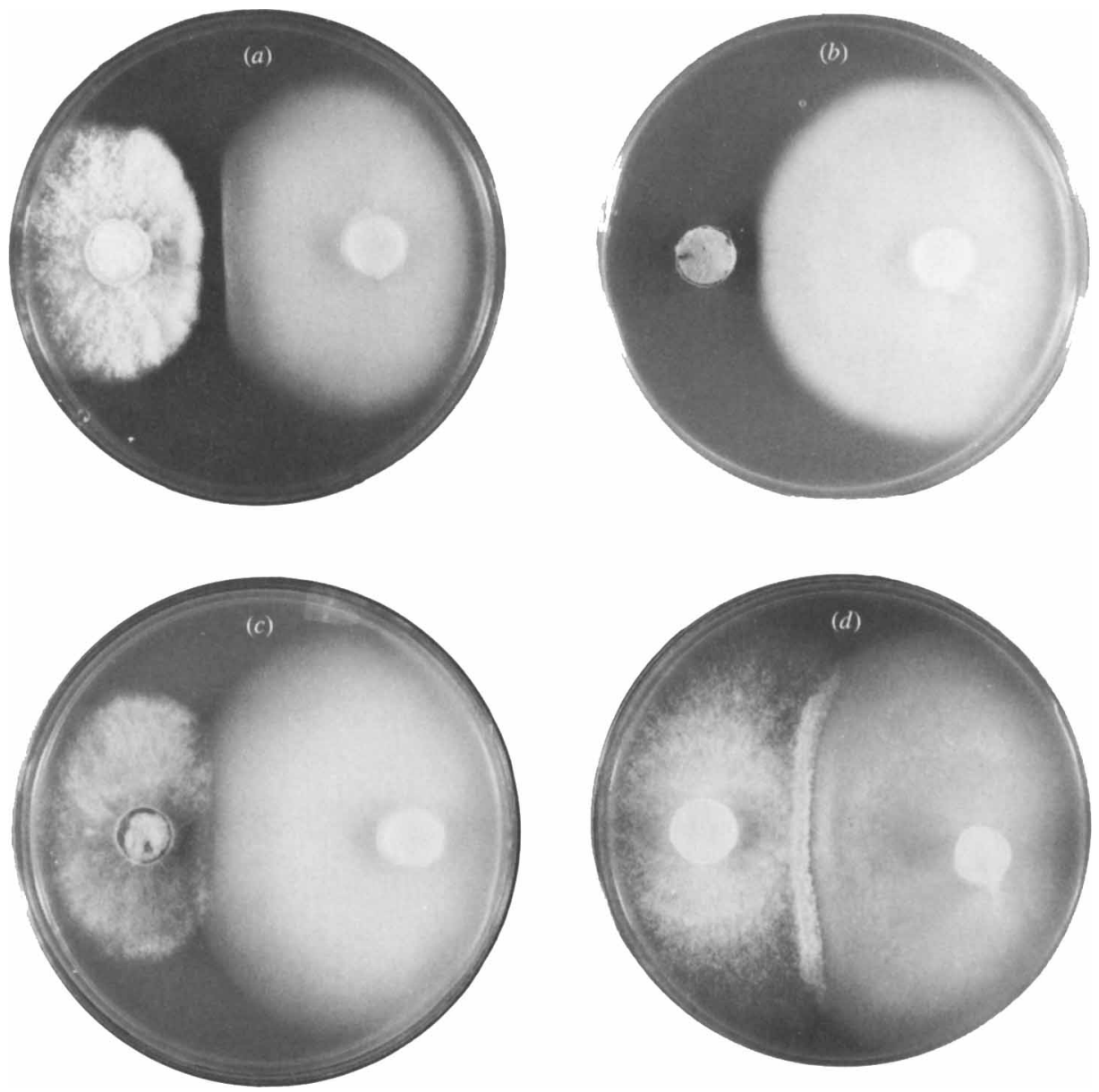

Fig. 2. Dual culture interactions between Sparassis crispa (right on all plates) and (a) Stereum sanguinolentum (mutual inhibition), (b) Heterobasidion annosum (growth strongly suppressed), (c) Rhizina undulata (no obvious inhibition) and (d) Phaeolus schweinit=ii (interaction line formation).

Table 1. Effects of antibiotic compounds from Sparassis crispa on extension of Botrytis cinerea germ tubes and mycelial growth of Heterobasidion annosum

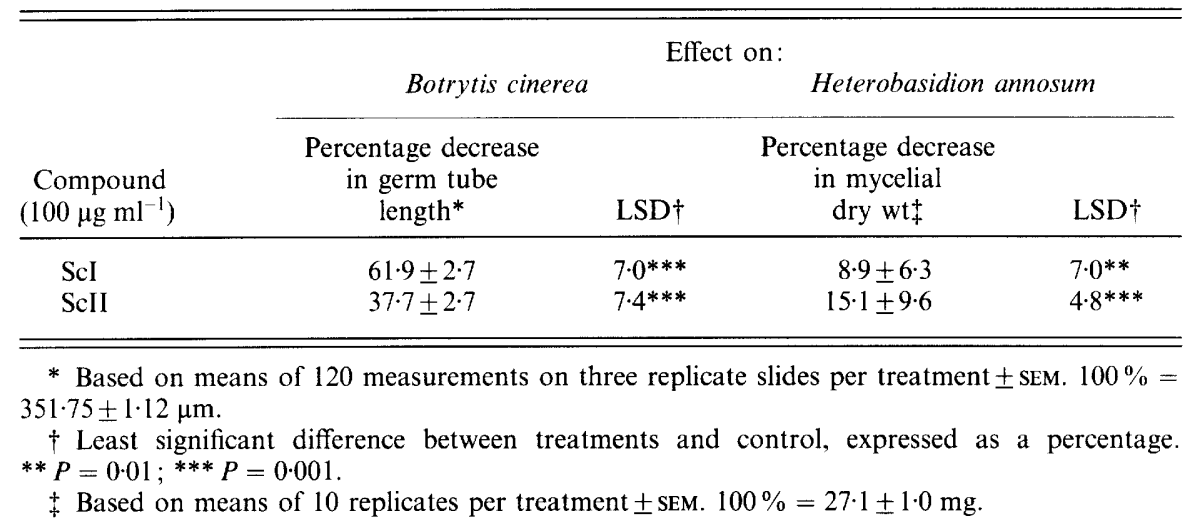

Accumulation of ScI and ScII in cultures of S. crispa

ScI (methyl orsellinate) comprised the major component of the shouldered peak, with a retention time of approximately $5.18 \mathrm{~min}$. The ScII shoulder appeared at a retention time of $5.83 \mathrm{~min}$. Throughout the incubation period, the peak height ratio ScI:ScII remained essentially constant between 3.8 and $4 \cdot 1$, in both isolates 
Table 2. HPLC detection of antibiotics ScI and ScII in brown-rotted wood of conifers and the decay fungi isolated from these trees

+ , Detected; - , not detected.

\begin{tabular}{|c|c|c|}
\hline Tree & $\mathrm{ScI}+\mathrm{ScII}$ & Fungus isolated \\
\hline 1. Sitka spruce & + & Sparassis crispa \\
\hline 2. Larch & - & $\begin{array}{l}\text { Undetermined. White, rapidly } \\
\text { growing mycelium }\end{array}$ \\
\hline 3. Larch & - & $\begin{array}{l}\text { Undetermined. White, rapidly } \\
\text { growing mycelium }\end{array}$ \\
\hline 4. Corsican pine & - & Phaeolus schweinitzii \\
\hline 5. European larch & - & P. schweinitzii \\
\hline 6. European larch & + & S. crispa \\
\hline 7. European larch & + & S. crispa \\
\hline 8. European larch & - & P. schweinitzii \\
\hline 9. European larch & - & P. schweinitzii \\
\hline 10. European larch & - & P. schweinitzii \\
\hline 11. European larch & - & P. schweinitzii \\
\hline 12. European larch & - & P. schweinitzii \\
\hline 13. European larch & - & P. schweinitzii \\
\hline 14. Corsican pine & + & S. crispa \\
\hline 15. European larch & + & S. crispa \\
\hline 16. European larch & $+^{*}$ & S. crispa \\
\hline 17. European larch & - & P. schweinitzii \\
\hline 18. European larch & - & P. schweinitzii \\
\hline
\end{tabular}

* Very small peaks at a retention time of about $14 \mathrm{~min}$ in this sample.

examined. Total antibiotic levels $(\mathrm{ScI}+\mathrm{ScII})$ and fungal biomass production for $S$. crispa isolates $5 \mathrm{~B}$ and $5 \mathrm{C}$ are shown in Fig. 3.

Although growth curves for the two isolates were closely similar, the onset of antibiotic production was later in $5 \mathrm{~B}$ than $5 \mathrm{C}$ : mean concentrations of total antibiotics in culture filtrates after 8 weeks were 39 and $65 \mu \mathrm{g} \mathrm{ml}^{-1}$, respectively. However, variation between individual replicate flasks was large.

\section{Detection of antibiotics in decayed wood}

Zones of antifungal activity were detected at $R_{F}$ values of 0.44 and 0.53 in solvent system $\mathrm{B}$, corresponding to $\mathrm{ScI}$ and ScII, but not at $R_{F} 0 \cdot 65-0 \cdot 70$ (sparassol). Quantitative estimations of the two active compounds were $102 \pm 44 \mu \mathrm{g}(\mathrm{g} \text { fresh } \mathrm{wt})^{-1}(\mathrm{ScI})$ and $90 \pm 13 \mu \mathrm{g}$ (g fresh $\mathrm{wt})^{-1}$ (ScII).

Gradient HPLC of extracts from the decayed Sitka spruce wood revealed a shouldered peak at retention time $14.1 \mathrm{~min}$, corresponding to ScI and ScII. A peak at 18.4 min may relate to sparassol, although the identity was not confirmed (Fig. 4).

Double or merged peaks, eluting with retention times between 13.5 and $14.2 \mathrm{~min}$, were observed in HPLC separations of 6 out of 18 brown rotted wood samples. S. crispa was isolated from the same 6 wood samples,

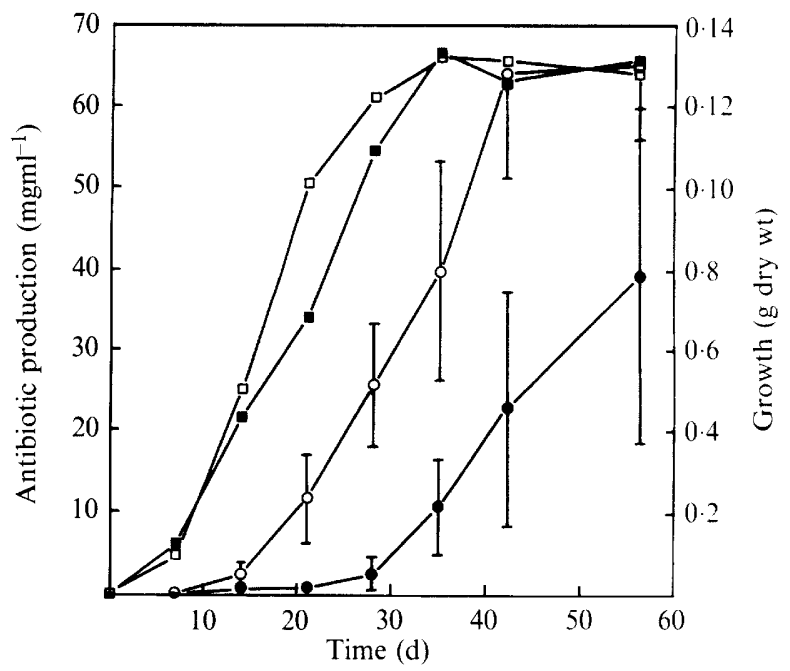

Fig. 3. Growth $(\square, \boldsymbol{\square})$ and antibiotic accumulation $(O, \mathbf{0}$; Scl plus ScII) in liquid cultures of Sparassis crispa $(\square, 0,5 \mathrm{~B} ; \mathbf{0}, 0.5 \mathrm{C})$. Vertical bars represent standard errors.

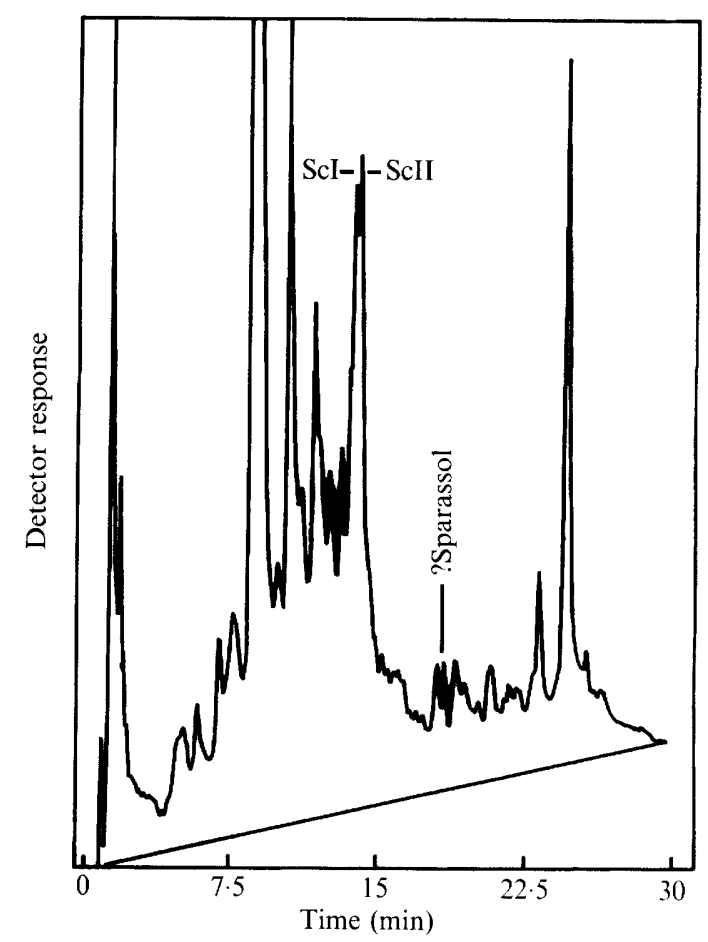

Fig. 4. Detection of ScI, ScII and (possibly) sparassol in methanol extracts of Sitka spruce wood decayed by Sparassis crispa, separated by HPLC. Compounds were separated on a Waters NovaPak-C18 cartridge column $(100 \mathrm{~mm} \times 8 \mathrm{~mm}$ i.d.) eluted with $60 \%$ methanol in water at a flow rate of $1.5 \mathrm{ml} \mathrm{min}-1$. Absorbance of the eluate was monitored at $266 \mathrm{~nm}$.

whereas other species of decay-causing fungi were cultured from the remaining 12 trees (Table 2).

\section{HPLC of sparassol crystals}

Sparassol eluted in the HPLC gradient at about $18.2 \mathrm{~min}$ 
as a single peak. Only trace quantities of ScI and ScII $\left(<1 \%\right.$ total $\left.A_{266}\right)$ were present in the methanol solution of these crystals.

\section{Discussion}

Three antifungal orsellinic acid derivatives were produced by $S$. crispa in culture and in wood decayed by this species. The previously described sparassol appears to be the least active, although it is possible that its high vapour pressure (Cwielong, 1986) resulted in loss during sample preparation. The identity of sparassol was inferred from its chromatographic properties, which were identical to those of crystals harvested from old cultures of $S$. crispa, the original source of sparassol (Falck, 1923).

The two more active compounds, ScI and ScII, were purified and characterized in the present study. ScI was identified as methyl-2,4-dihydroxy-6-methylbenzoate (methyl orsellinate) and ScII as a methyl-dihydroxymethoxy-methyl benzoate. In the latter compound, one of the hydroxyl groups occupies the 2-position: the relative positions of the second hydroxy-group and the methyl- and methoxy- groups remain to be determined. It is likely that a major part of the antifungal activity that Falck (1923) observed preventing the contamination of old cultures was attributable to ScI and ScII, rather than to sparassol.

Antifungal orsellinic acid derivatives are also known in other fungi. A series of sesquiterpene orsellinates has been isolated and characterized from cultures of Armillaria mellea and A. ostoyae (Donnelly et al., 1982, 1984; Medland et al., 1982), and orsellinic acid itself is reported to exhibit antibacterial and antifungal activity (Lennartz, 1947; Fujikawa et al., 1956; 1970; Cwielong, 1986). Although inhibition of other fungi by $S$. crispa may be due to the effects of these compounds, and growth of Heterobasidion annosum, which is strongly inhibited by $S$. crispa on agar plates, was reduced by purified ScI and ScII, the data available are insufficient for proof.

In an early survey, the rate of extension and antibiotic production among a range of 500 basidiomycetes appeared to be negatively correlated (Hervey, 1947). $S$. crispa is particularly slow growing in culture compared with other wood decay fungi (Stalpers, 1978). Although self-inhibition provides a possible explanation for this effect, rapid early growth of cultures before compounds $\mathrm{ScI}$ and ScII had begun to accumulate was not apparent (Fig. 3). Also, growth of isolates 5B and 5C was closely similar, despite their different patterns of antibiotic accumulation.

Overall, the patterns of accumulation of ScI and ScII observed parallel those of the phytotoxic fomajorins produced by $H$. annosum (Donnelly et al., 1987). Despite the phytotoxic nature of the fomajorins, the disease syndrome caused by $H$. annosum does not appear typically toxin-mediated. It has been postulated that the biological role of the fomajorins is in the infection process (Sonnenbichler et al., 1989). However, as they are also produced in interactions with antagonistic fungi (Sonnenbichler et al., 1989) they may be important in the long-term maintenance of the fungus in resources (cf. Rayner \& Boddy, 1988) captured initially in the living tree. $H$. annosum is capable of survival for many years in buried wood (e.g. stumps) (Phillips \& Burdekin, 1982).

Other root- and butt-rot fungi, including Phaeolus schweinitzii, also persist for prolonged periods in the decayed wood of stumps initially infected when the trees were living (Barrett, 1985). In the living tree, the endogenous defences of the host may serve to exclude other micro-organisms from competition with such decay fungi, but this protection ceases on death of the host (Gramss, 1987) and the residual tissues, comprising the stump, then become available to a wide range of colonizers (cf. Rayner \& Boddy, 1988). The present study has demonstrated that $\mathrm{ScI}$ and ScII occur naturally in wood decayed by $S$. crispa, at concentrations sufficient to impair the growth of other fungi. It seems possible, therefore, that these compounds may contribute to the suppression of potential competitors, hence allowing $S$. crispa to persist for an extended period. The production of antifungal compounds by many wood-decay fungi, e.g. P. schweinitzii (S. Woodward, unpublished data) suggests that such effects may be widespread among these fungi.

Detection by HPLC of ScI and ScII in extracts of conifer wood (which in some cases had been exposed to environmental weathering) decayed by $S$. crispa, but not in wood decayed by other brown rot fungi, notably $P$. schweinitzii, may provide the basis for a rapid diagnostic method. This technique would obviate the requirements for basidiome production, which is often sporadic, or isolation of the causal fungi, which can be problematic. especially from wood in an advanced state of decay. Moreover, the widespread production of antibiotic secondary metabolites by wood-inhabiting fungi suggests that this approach may be more generally applicable.

We thank Drs M. R. Kemp and M. Lewis of Long Ashton Research Station, University of Bristol for their assistance in the characterization of ScI and ScII. S.W. acknowledges the financial support of the Agricultural and Food Research Council for part of this work.

\section{References}

Barrett, D. K. (1985). Basidiospores of Phaeolus schreinitzii: a source of soil infestation. European Journal of Forest Pathology 15. $417-425$. 
Brian, P. W. (1951). Antibiotics produced by fungi. Botanical Review 17, 357-430.

Broadbent, D. (1968). Antibiotics produced by fungi. Pest Articles and News Summaries 14, 120-141.

Cwielong, P. (1986). Mechanismen der Resistenz und der Pathogenität von fungizid wirksamen Naturstoffen gegenuber dem Erreger der Rotfäule Heterobasidion annosum (Fr.) Bref. PhD dissertation, Universität Göttingen, Germany.

Donnelly, D., Sanada, S., O'Reilly, J., Polonsky, J., Prangé, T. \& PASCARD, C. (1982). Isolation and structure (X-ray analysis) of the orsellinate of armillol, a new antibacterial metabolite from Armillaria mellea. Journal of the Chemical Society. Chemical Communications (1982) 135-137.

Donnelly, D. M. X., Polonsky, J., Prangé, T., Snatzke, G. \& WAGNER, U. (1984). The absolute configuration of the orsellinate of armillol: application of the coupled oscillator theory. Journal of the Chemical Society. Chemical Communications (1984) 222-223.

Donnelly, D. M. X., O’Reilly, J., Polonsky, J. \& Sheridan, M. H. (1987). In vitro production and biosynthesis of fomajorin $\mathrm{D}$ and $\mathrm{S}$ by Fomes annosus (Fr.) Cooke. Journal of the Chemical Society. Perkin Transactions (1987) 1869-1872.

FALCK, R. (1923). Über ein krystalliscertes Stoffwechsel produkt von Sparassis ramosa Schaff. Berichte der Deutschen Chemischen Gesellschaft (Berlin) 56, 2555-2556.

Fisher, P. J. \& ANSON, A. E. (1983). Antifungal effects of Massarina aquatica growing on oak wood. Transactions of the British Mycological Society 81, 523-527.

Fujikawa, F., Hitosa, Y., Yagi, Y. \& Yasuda, K. (1956). Antiseptics for foodstuff. LX. Yakugaka Zasshi 76, 674-678.

Fujikawa, F., Hirayama, T., Nakamura, Y., Suzuki, M., Dol, M. \& NIKI, C. (1970). Studies for antiseptics for foodstuff. LXXI. Studies on orsellinic acid ester, $p$-orcinolcarboxylic acid ester and olivetonide as a preservative for saki. Yakugaka Zasshi 90, 1517-1519.

Gramss, G. (1987). The infiuence of the concomitant microflora on establishment and dieback of decay fungi in standing timber. Journal of Phytopathology 120, 205-215.

Hervey, A. H. (1947). A survey of 500 basidiomycetes for antibacterial activity. Bulletin of the Torrey Botanical Club 74, 476-503.

Homans, A. L. \& FuChS, A. (1970). Direct bioautography on thinlayer chromatograms as a method for detecting fungitoxic substances. Journal of Chromatography 51, 327-329.

HütTermanN, A. (1987). History of forest botany (Forstbotanik) in Germany from the beginning in 1800 until 1940 - Science in the tension field between university and professional responsibility. Berichte der deutschen botanische Gesellschaft 100, 107-141.

LAST, F. T. \& HANLEY, R. E. (1956). A local lesion technique for measuring the infectivity of conidia of Botrytis fabae Sardiña. Annals of Applied Biology 44, 410-418.

LENNARTZ, T. (1947). Über antituberkulöse Stoffe: Antibiosche
Eigenschaften von Derivaten des Orcins. Zeitschrift fiur Naturforschung 2 B, 7-9.

Mathieson, J. (1946). Antibiotics from Victorian basidiomycetes. Australian Journal of Experimental Biology and Medical Science 24 $57-62$.

Medland, S. L., Izak, R. R., Wing, R. M., Zaki, A. I., Munnecke, D. E. \& Sims, J. J. (1982). Melleolide, a new antibiotic from Armillaria mellea. Tetrahedron Letters 23, 2515-2518.

Phillips, D. H. \& Burdekin, D. A. (1982). Diseases of Forest and Ornamental Trees. London: Macmillan.

RaYNer, A. D. M. \& Boddy, L. (1988). Fungal Decrmposition of Wood. Chichester: John Wiley.

Robbins, W. J., Hervey, A., Davidson, R. W., MA, R. \& Robbins, W. C. (1945). A survey of some wood-destroying and other fungi for antibacterial activity. Bulletin of the Torrey Botanical Cluh 72. 165-190.

Rossall, S. \& Mansfield, J. W. (1978). The activity of wyerone acid against Botrytis. Annals of Applied Biology 89,359 362.

SiEPMANN, R. (1987). Wachstumshemmung von Stammfaulepilzen und von Gremmeniella abietina durch Bacillus subtilis. European Journal of Forest Pathology 17, 59-64.

Sonnenbichler, J., Blieste, I. M., Peipp, H. \& Holdenrieder. O. (1989). Secondary fungal metabolites and their biological activities. I. Isolation of antibiotic compounds from cultures of Heterobasidion annosum synthesized in the presence of antagonistic fungi or host plant cells. Biological Chemistry Hoppe-Seyler 370, 1295-1303.

STALPERS, J. A. (1978). Identification of wood-inhabiting fungi in pure culture. Studies in Mycology no. 16. Baarn: Centraalbureau voor Schimmelcultures.

WedeKind, E. \& FleisCher, K. (1923). Über die Konstitution des Sparassols. Berichte der deutschen chemischen Gescllschaft $\mathbf{5 6}$ $2556-2563$

WEDEKIND, E. \& Fleischer, K. (1924). Zur Kenntnis des Sparassols. Berichte der deutschen chemischen Gesellschaft 57, (Abt. B). 1121-1123.

Wilkins, W. H. (1945). Investigation into the production of bacteriostatic substances by fungi. Cultural work on basidiomycetes. Transactions of the British Mycological Society 28, 110-114.

WILKINS, W. H. (1946). Investigation into the production of bacteriostatic substances by fungi: preliminary examination of the fifth 100 species, all basidiomycetes, mostly of the wood-destroying type. British Journal of Experimental Pathology 27, 140-142.

Wilkins, W. H. \& HaRRIS, G. C. M. (1944). Investigation into the production of bacteriostatic substances by fungi. VI. Examination of the larger basidiomycetes. Annals of Applied Biology' 31, $261-270$.

Woodward, S. \& Pearce, R. B. (1988). The role of stilbenes in resistance of Sitka spruce (Picea sitchensis (Bong.) Carr.) to entry of fungal pathogens. Physiological and Molecular Plant Pathology 33, 127-149. 